\title{
Reglas de dimensionamiento en trazas tardogóticas españolas. Las catedrales de Sevilla y Segovia
}

\section{Dimensioning rules in Spanish Late Gothic traces. The Seville and Segovia Cathedrals}

\author{
A. García-Ortega ${ }^{(*)}$
}

RESUMEN

Los criterios de diseño y dimensionamiento de las estructuras góticas aún nos son en gran medida desconocidos, y particularmente en España al carecer de una tratadística coetánea similar a la centroeuropea. Ésta evidencia un sencillo proceder a través de reglas numéricas o geométricas, y cuyo paralelo se pretende detectar en nuestro contexto.

Para ello se recurre al análisis de las trazas catedralicias de Sevilla y Segovia, dibujadas a escala e incluso con algunas cotas dimensionales rotuladas, especificando luces y secciones de pilares y muros. Estos elementos, junto con los contrafuertes, constituían la estructura portante vertical, y son el objeto principal de estudio, tomando como referente la tratadística centroeuropea. Ello ha permitido formular hipótesis sobre las posibles reglas estructurales al uso en nuestro país, que se utilizarían establecer un primer dimensionamiento, plasmado en la traça general del edificio. Éste sería suficiente para comenzar la fábrica con razonables garantías de viabilidad.

Palabras clave: dimensionamiento; estructura; gótico; reglas; traza; Sevilla; Segovia; catedral.

\section{ABSTRACT}

The design and dimensioning criteria of the Gothic structures are currently not well known. This is exacerbated in the Spanish case, by the lack of coeval treaties like the Central European ones. These compile many simple numerical and geometrical rules, which could be analogous to the Spanish ones.

These will be studied based on the cathedral traces of Seville and Segovia, drawn to scale and with labelled dimensions, specifying the length and width of the different building parts, and the pillars and walls sections. These elements and the buttresses compose the vertical structure. They are the main purpose of this study, for which the Late Gothic treaties are considered as a reference. Different hypotheses about the Spanish structural rules have been formulated, which could have been used by the masters for an initial dimensioning, drawn in the trace. This was enough to start the building ensuring technical feasibility.

Keywords: dimensioning; structure; Gothic; rules; trace; Seville; Segovia; Cathedral.

${ }^{(*)}$ E.T.S. de Arquitectura, Universidad de Sevilla (Sevilla, España).

Persona de contacto/Corresponding author: agarcia11@us.es (A. García-Ortega)

ORCID: http://orcid.org/oooo-0oo1-5907-5283 (A. García-Ortega)

Cómo citar este artículo/Citation: García-Ortega, A. (2016). Reglas de dimensionamiento en trazas tardogóticas españolas. Las catedrales de Sevilla y Segovia. Informes de la Construcción, 69(545): e177, doi: http://dx.doi.org/10.3989/ic.15.147.

Copyright: (C) 2017 CSIC. Licencia / License: Salvo indicación contraria, todos los contenidos de la edición electrónica de Informes de la Construcción se distribuyen bajo una licencia de uso y distribución Creative Commons Attribution License (CC BY) Spain 3.o. 


\section{INTRODUCCIÓN}

Tras siglos de su construcción el diseño estructural de las catedrales góticas sigue siendo objeto de interés y estudio, recurriéndose frecuentemente a los sofisticados métodos y herramientas de análisis que hoy tenemos a nuestra disposición. Pero éstos, ni los más básicos conocimientos de las leyes de la estática o la resistencia de materiales, estaban al alcance de los maestros medievales que concibieron, y dimensionaron, los edificios (1), por lo que en buena medida desconocemos cuales fueron los verdaderos criterios proyectuales de estas sorprendentes estructuras. Esta última cuestión, más que el análisis del comportamiento estructural de lo finalmente construido, constituye el objeto del presente estudio, particularizado en el ámbito peninsular. Para ello se seleccionan dos significativos casos del tardogótico español, que cuentan además con trazas tempranas: las catedrales de Sevilla y Segovia, iniciadas respectivamente en 1433-1334 y 1525, y entre las cuales incluso se han postulado ciertos vínculos ${ }^{1}$ (Figuras 1 y 2).

Más allá de un irracional proceso de tanteo y error, tenemos suficientes indicios de que hubo una scientia medieval de las estructuras (2), aunque muy diferente a los actuales métodos científicos. Así algunos tratados tardogóticos centroeuropeos recogen la aplicación de sencillas reglas de naturaleza geométrica o numérica, que a modo de recetas servían para controlar las proporciones y dimensiones de los espacios y de los distintos elementos estructurales y formales. Esto permite suponer que en el contexto español operó un proceder semejante, aunque carezcamos de un corpus teórico coetáneo análogo, ya que los tratados tardíos de los siglos XVI y xvII ofrecen dudas sobre si verdaderamente responden al saber medieval; así, por ejemplo, el valioso «Compendio» de Simón García (3) recogió algunos conocimientos de Rodrigo Gil de Hontañón, pero de su etapa final, y muchas de las propuestas gráficas pudieran ser una reelaboración humanística del autor (4).

Por ello el problema se abordará a partir del análisis de las valiosas trazas subsistentes de los dos edificios señalados, en las que pudieron aplicarse los criterios de dimensionamiento estructural al uso, como apunta la gran concordancia detectada entre algunos dibujos de planta centroeuropeos y la propia tratadística coetánea en este ámbito geográfico (2). Estas trazas son las únicas góticas subsistentes en nuestro país que abarcan la totalidad del proyecto del edificio, estando realizadas a escala e incluso con algunas cotas. Entre el nutrido

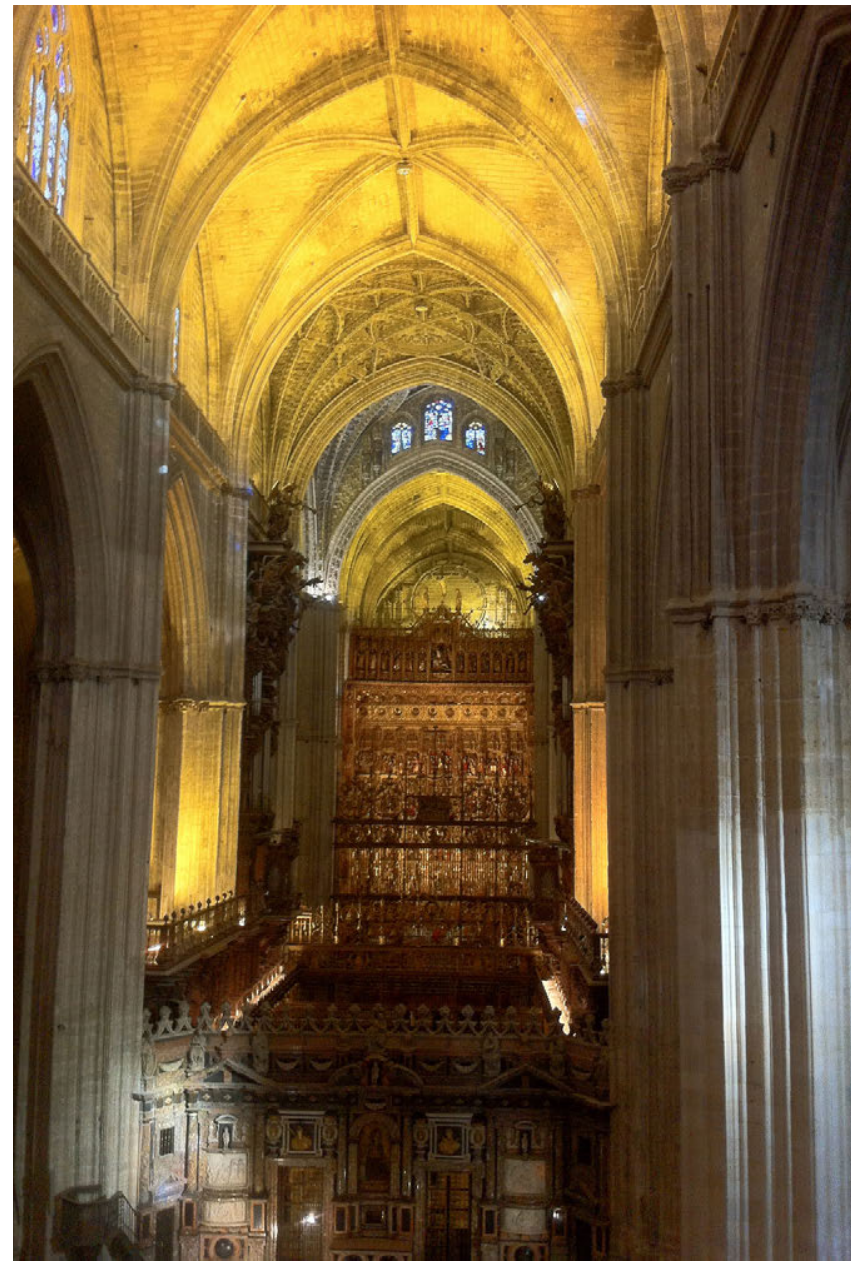

Figura 1. Catedral de Sevilla. Nave central.

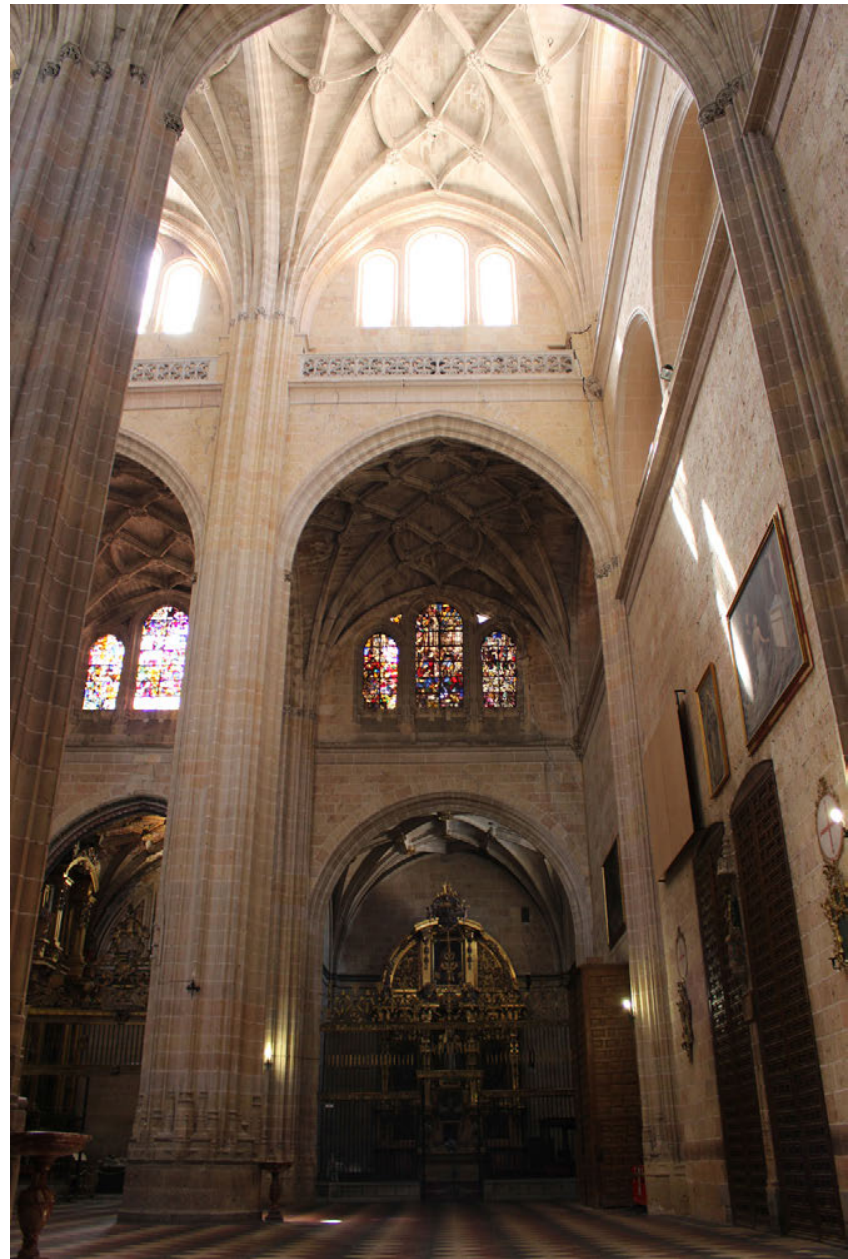

Figura 2. Catedral de Segovia. Tramo formado por nave central, laterales y capillas hornacinas.

\footnotetext{
Para la sede segoviana se pidieron las trazas de la hispalense, e incluso el maestro de la primera, Juan Gil, intervino en Sevilla tras el derrumbe del cimborrio (1511).
} 
conjunto de planos del Archivo catedralicio segoviano existen dos plantas en pergamino, así como dos dibujos de las elevaciones previstas, superponiendo alzado y sección transversal del templo². De Sevilla sólo nos ha llegado una planta en papel, el conocido como "plano de Bidaurreta» ${ }^{3}, \mathrm{y}$, aunque no tenemos un dibujo del desarrollo en altura del edificio, las cotas altimétricas rotuladas en el mismo indican que debió de haberlo.

El estudio de los criterios de dimensionamiento estructural operantes en el tardogótico español considerará el referente de la tratadística centroeuropea, lo que además permitirá valorar tanto las supuestas analogías como las especificidades locales. Por otro lado, las trazas seleccionadas permiten establecer significativas comparaciones a distintos niveles. Así, el hecho de que entre las dos catedrales medie casi un siglo supone un test sobre la posible evolución de las reglas estructurales en el ámbito peninsular, y también, al contar en el caso segoviano con dos plantas prácticamente coetáneas, se traslucen interesantes indicios sobre la heterogénea aplicación de los criterios a un mismo problema arquitectónico. Por último, se contrastarán las secciones resistentes de proyecto con las finalmente construidas, que, sorprendentemente, fueron sistemáticamente reducidas para muchos elementos.

\section{OBJETO, METODOLOGÍA Y BASES DE ANÁLISIS}

El proyecto del edificio gótico partía del dibujo de su planta, la traça, y que en la época podía llevar implícitos aspectos de espacialidad, estructura o sistema de cubrición, aunque a menudo no pasaba de una somera previsión. La misma podía acompañarse a veces de una «elevación» (sección, alzado o incluso una mezcla de ambas), de mayor o menor esquematismo, y como se ha señalado para el caso segoviano podía no ser mucho más que un "ensayo para controlar las alturas» (8). Esto sugiere que no existía una reflexión y análisis rigurosos del comportamiento estructural del conjunto o de la incidencia del tipo de bóvedas ${ }^{4}$, tal y como hoy lo podríamos entender. Incluso el abovedamiento o la altura del edificio eran frecuentemente cuestionados o cambiados durante las obras, siendo objeto de agrios debates y contradictorios informes de expertos.

Por todo ello, y porque los tratados centroeuropeos establecen sus reglas a partir de magnitudes implícitas en la planta, el análisis se centrará en el dimensionamiento establecido en el dibujo de las mismas, recurriendo a las elevaciones sólo como indicador de la previsión de alturas del edificio y sus elementos. Se estudiará la solución estructural «tipo» de los cuerpos de naves, generados modularmente yuxtaponiendo un esquema formado por capillas hornacinas, naves laterales (dobles en Sevilla) y central (Figuras 3, 4 y 5) ${ }^{5}$. Estos espacios están conformados en planta por un conjunto de pilares y muros, éstos con sus contrafuertes, elementos que serán en definitiva el objeto exclusivo de estudio, constituyen la estructura vertical del edificio, autoportante y estable de por sí, siendo además en el proceso constructivo una primera fase realizable sólo con andamios (4). Su dibujo en la traça suponía establecer para ellos un primer dimensionamiento, que será estudiado tanto a partir del tamaño grafiado en los planos, a escala, como por las cotas a veces explícitamente rotuladas (Figura 6).

Las hipótesis formuladas serán coherentes con los modos de hacer de los maestros góticos, cuyo nivel de conocimientos era eminentemente práctico, alejado de cualquier razonamiento o especulación teórica (10). Así lo reflejan tres importantes tratados tardogóticos alemanes, los únicos conocidos que recogen determinaciones estructurales, y que han sido transcritos por Coenen (11): las Unterweisung (Instrucciones) de Lorenz Lechler (12), y otros dos anónimos, Von des Chores Maß und Gerechtigkeit (Sobre la Medida y Proporción del Coro) y el Wiener Werkmeisterbuch (Tratado de Viena, h. 1450).

Sus reglas, extraídas de la experiencia, no eran dogmáticas, aplicándose con lógica y flexibilidad según el criterio del maestro; esto a su vez daría cabida a la consideración de múltiples factores, como la calidad del material, aludida expresamente por Lechler, o la formalización constructiva de los elementos. No obstante, dichas reglas se basaban ante todo en simples relaciones de proporción, a las que confiaban el éxito estructural, subyaciendo una «ley de semejanza»; ésta, aunque errónea teóricamente, era válida en la práctica para la mayoría de las obras de fábrica (13), que por sus bajas tensiones de trabajo tienen como el principal problema la estabilidad (14). Por ello, más que el estado tensional, se pretende analizar la forma y dimensión de cada elemento, en sí y en relación al conjunto.

Los tratados evidencian también cierta disociación entre el dimensionamiento de la planta, un proceso previo dotado de autonomía procedimental, y la problemática de la altimetría y cubrición del edificio. Sobre lo primero, objeto prioritario del estudio, nos ofrecen valiosos indicios sobre tres sustanciales aspectos, y que es necesario delimitar previamente al análisis de las trazas consideradas:

\section{- Los parámetros que interesaban a los maestros} para dimensionar cada tipo de sección resistente. Son siempre magnitudes sencillas y fácilmente objetivables, como espesores, diámetros, saliente (en contrafuertes), etc., y que eran determinadas teniendo en cuenta, implícita o explícitamente, las luces a salvar, así como las proporciones de los elementos concretos. Las secciones eran establecidas en el arranque, y podían decrecer en las partes superiores del elemento, aunque la altura total de

\footnotetext{
2 El estudio crítico más completo es de Ruiz (5).

3 Entre los numerosos trabajos destaca el de Alonso y Jiménez (6). Los aspectos de trazado han sido recientemente estudiados por GarcíaOrtega (7).

4 Esto ha sido recientemente analizado por Ramos (9), caracterizando la repercusión de rellenos, geometría, apuntamiento, espesor... Sin embargo, los tratados tardogóticos no abordan el problema en toda su complejidad, atendiendo principalmente al trazado de sus nervios, siendo muchos aspectos de difícil interpretación (2).

5 Contrariamente a las cabeceras, ambas naves catedralicias constituyen problemas estructurales análogos, con una sección transversal escalonada de similares luces y alturas. También las dos comenzaron por los pies, siguiendo fielmente el proyecto, más alterado a partir del crucero.
} 


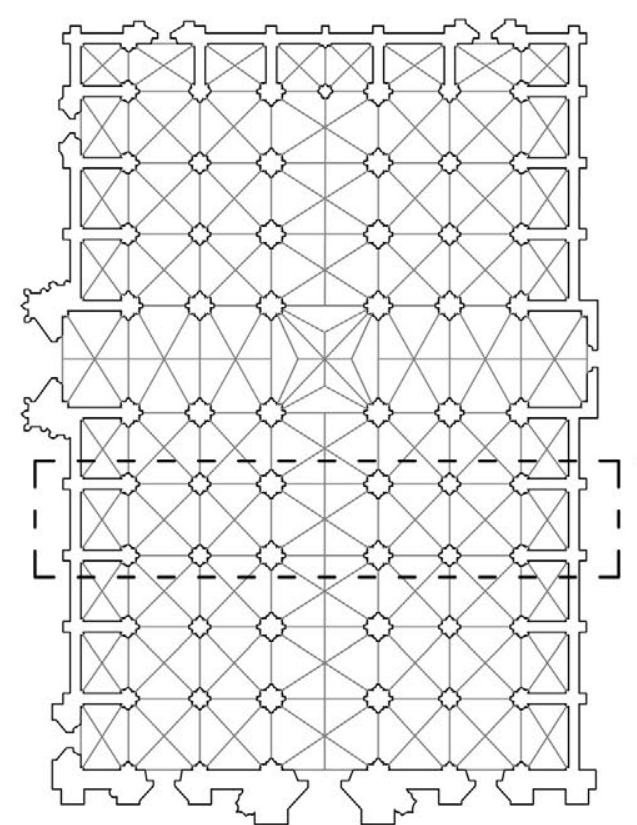

TRAMO TIPO

CATEDRAL DE SEVILLA:

ESQUEMA DE LA TRAÇA DE BIDAURRETA

பூ

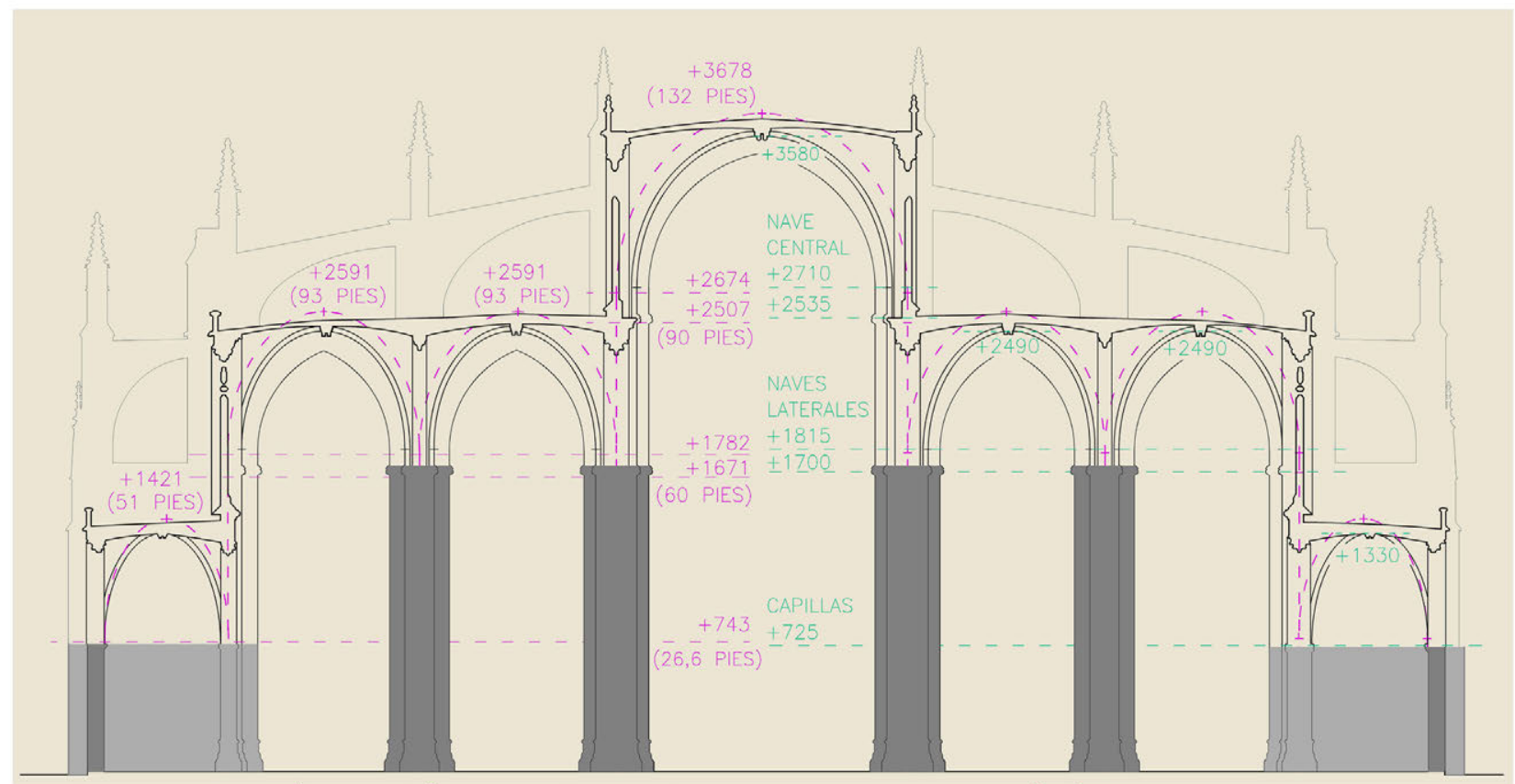

ELEVACIONES Y COTAS (CM Y PIES) SEGUN ESQUEMA TEORICO / COTAS CONSTRUIDAS (CM) DE CORNISAS, PERALTES Y CLAVES

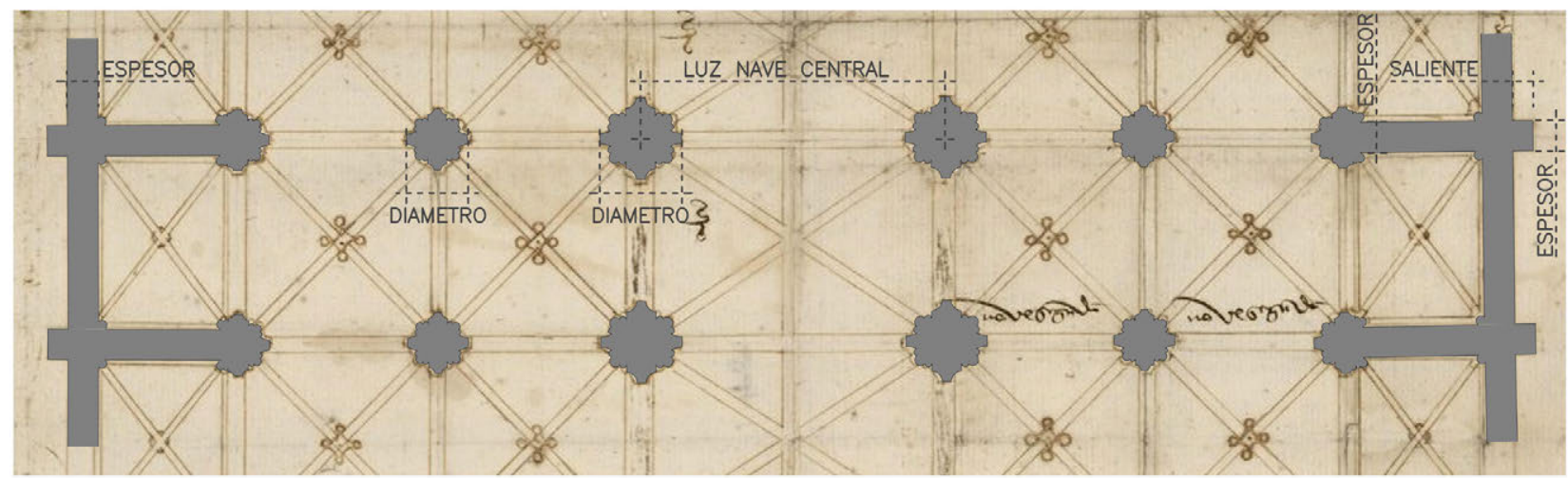

PLANTA DE TRAMO TIPO: ELEMENTOS DE LA ESTRUCTURA VERTICAL Y PARAMETROS CONSIDERADOS

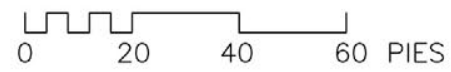

Figura 3. Catedral de Sevilla. Tramo tipo del cuerpo de naves en el «plano de Bidaurreta», indicando los parámetros considerados, e hipótesis altimétrica comparativa con lo construido, según García-Ortega (7). 


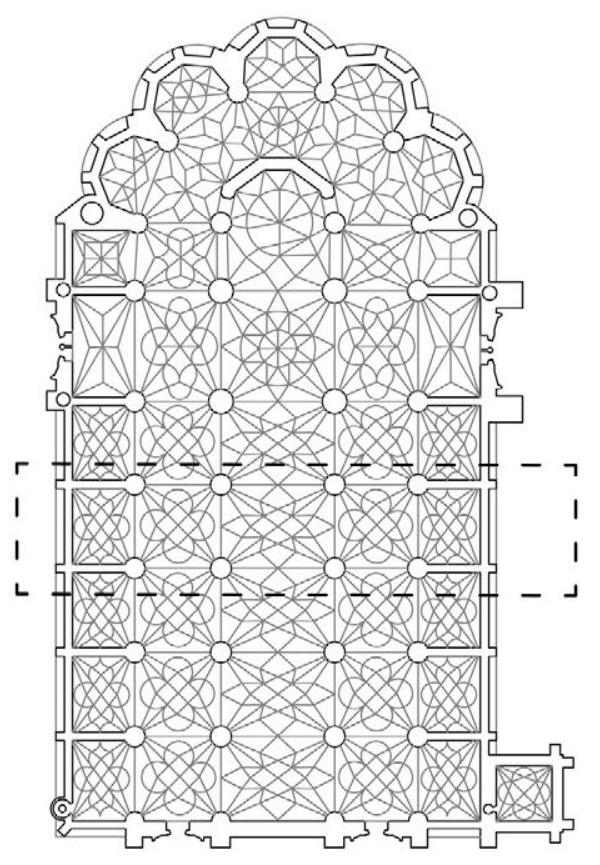

TRAMO TIPO

CATEDRAL DE SEGOVIA:

ESQUEMA DE LA TRAÇA DE JUAN GIL பூ

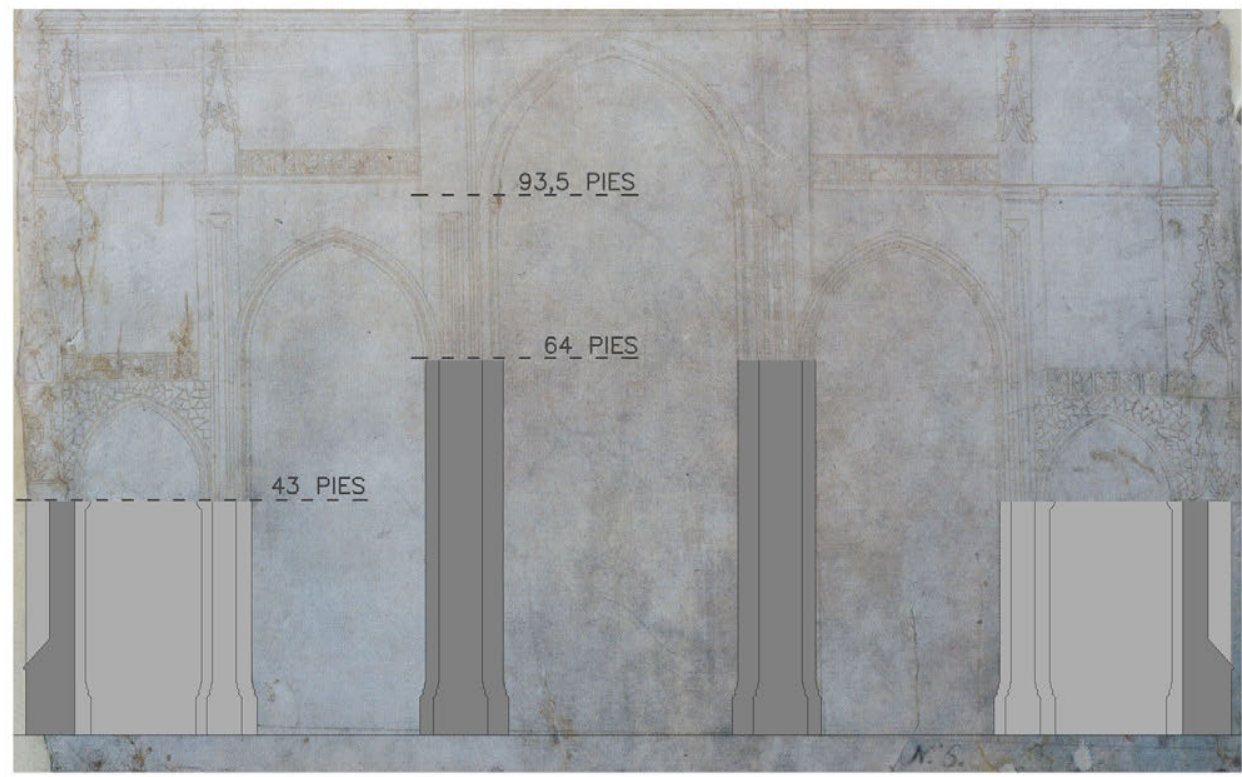

ELEMENTOS ESTRUCTURALES EN LA ELEVACION Y COTAS HASTA ARRANQUE DE BOVEDAS

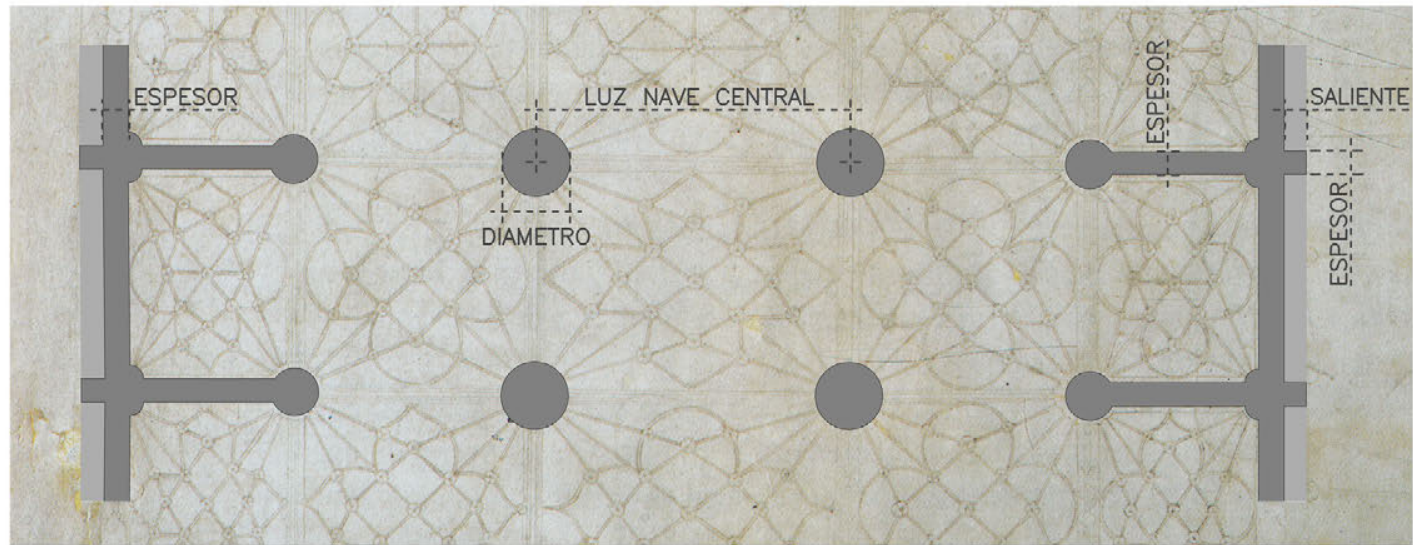

PLANTA DE TRAMO TIPO: ELEMENTOS DE LA ESTRUCTURA VERTICAL Y PARAMETROS CONSIDERADOS

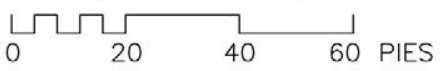

Figura 4. Catedral de Segovia. Tramo tipo del cuerpo de naves en el la planta de Juan Gil de Hontañón y en la elevación prevista, representadas a la misma escala, con indicación de los parámetros considerados. 

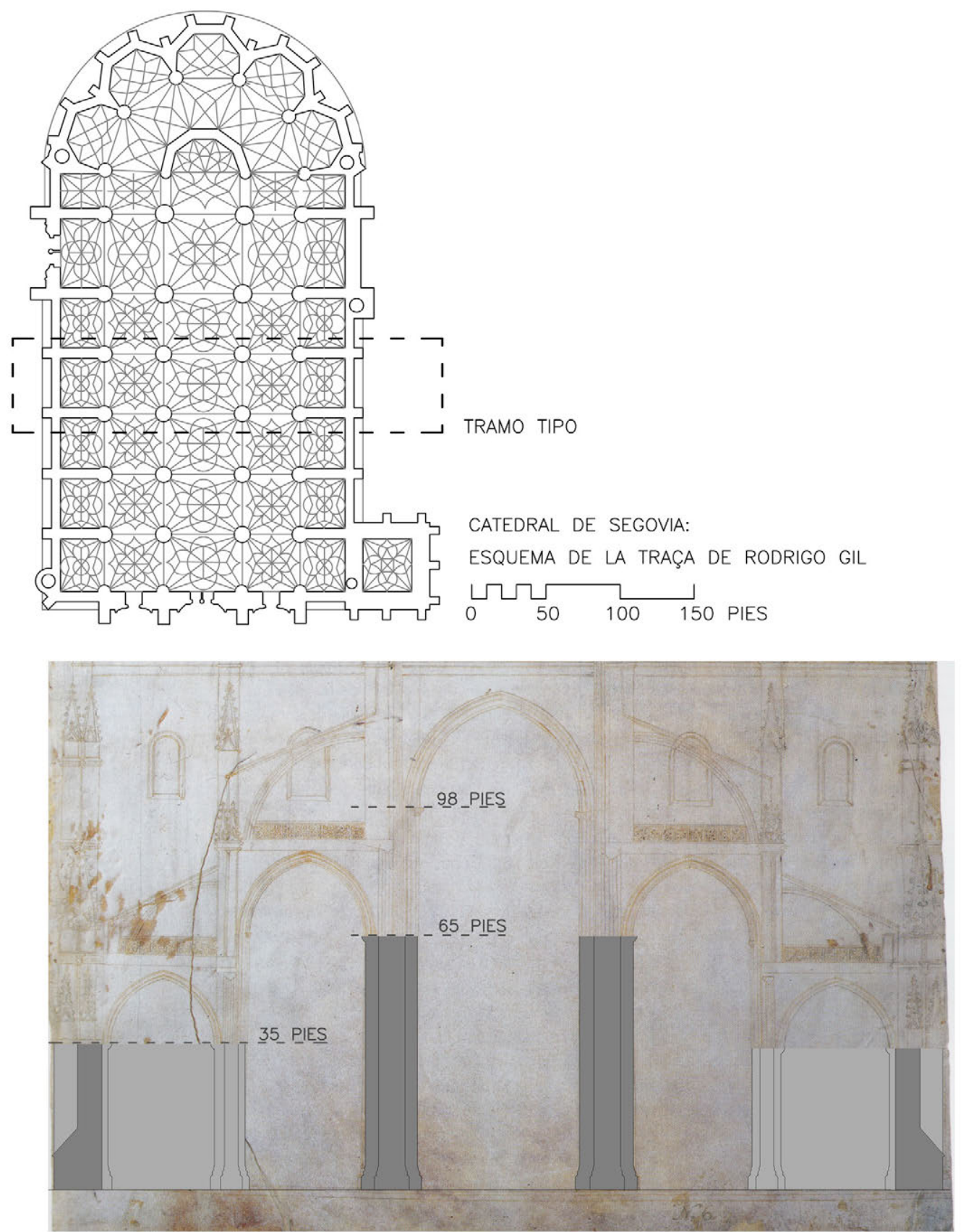

ELEMENTOS ESTRUCTURALES EN LA ELEVACION Y COTAS HASTA ARRANQUE DE BOVEDAS

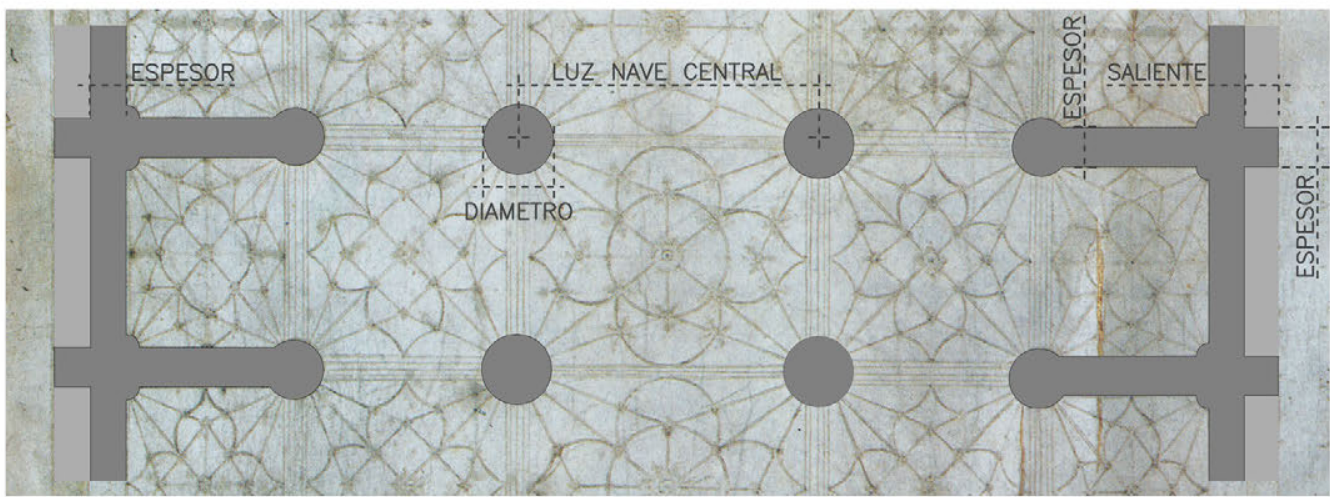

PLANTA DE TRAMO TIPO: ELEMENTOS DE LA ESTRUCTURA VERTICAL Y PARAMETROS CONSIDERADOS

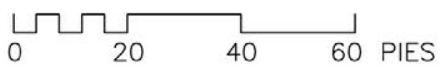

Figura 5. Catedral de Segovia. Tramo tipo del cuerpo de naves en el la planta de Rodrigo Gil de Hontañón y en la elevación prevista, representadas a la misma escala, con indicación de los parámetros considerados. 

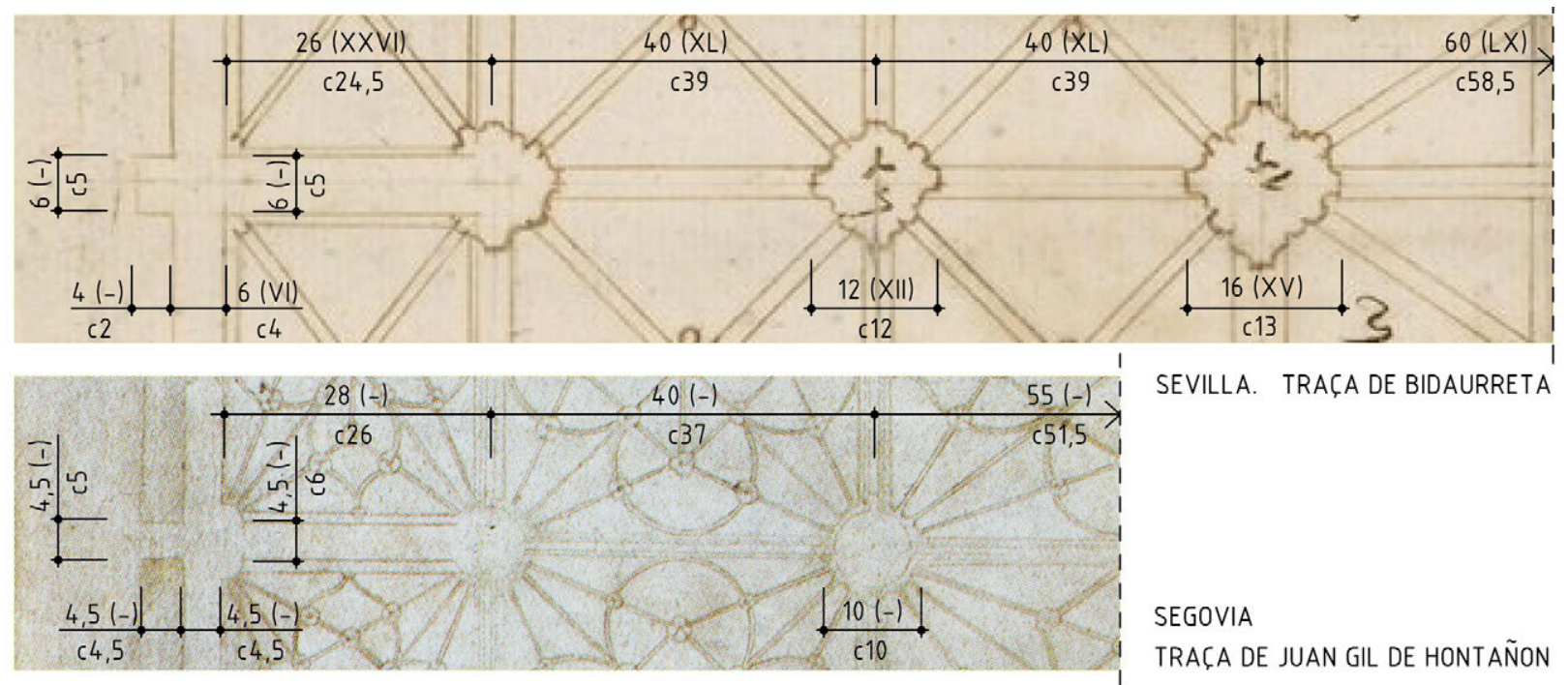

SEVILLA. TRAÇA DE BIDAURRETA

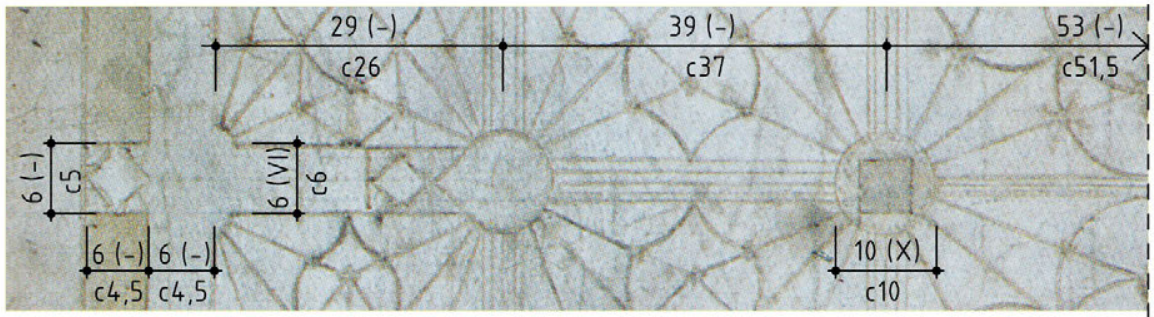

SEGOVIA

TRAÇA DE JUAN GIL DE HONTAÑON

SEGOVIA

TRAÇA DE RODRIGO GIL HONTAÑON

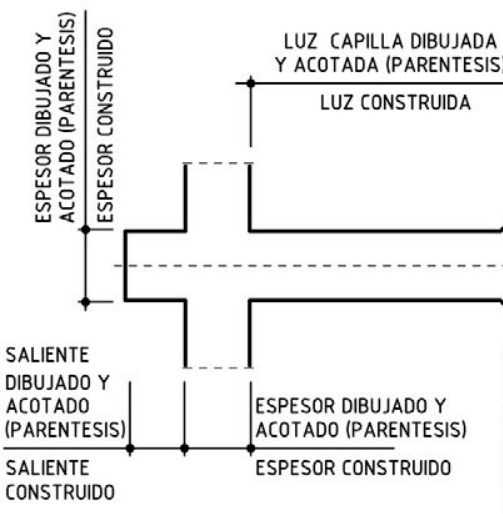

\begin{tabular}{|c|c|}
$\begin{array}{c}\text { LUZ NAVE LATERAL DIBUJADA } \\
\text { Y ACOTADA (PARENTESIS) }\end{array}$ & $\begin{array}{c}\text { LUZ CENTRAL DIBUJADA } \\
\text { Y ACOTADA (PARENTESIS) }\end{array}$ \\
\hline LUZ CONSTRUIDA & LUZ CONSTRUIDA \\
\hline
\end{tabular}$$
1
$$$$
1
$$$$
\text { 1 }
$$

ESQUEMA DE LOS PARAMETROS DIMENSIONALES EN SECTOR TIPO: DIMENSION DIBUJADA (SEGUN ESCALA), ROTULADA (NNO ROMANO) Y CONSTRUIDA ACOTADO (PARENTESIS) DIAMETRO CONSTRUIDO IIூ

Figura 6. Esquema de parámetros en sector tipo y dimensionamiento de pilares, muros y contrafuertes en las traças, representadas a la misma escala. Se indican en pies las luces y dimensión de los elementos: la dibujada según escala, la rotulada en cifras romanas (entre paréntesis) y lo finalmente construido (c).

éste, o incluso del edificio, no parece ser un dato de partida en el dimensionamiento. Sin embargo, este valor también sería considerado implícitamente, ya que el tratado de Lechler contiene referencias altimétricas para el edificio, oscilando entre 1,5 y 3 veces la luz del coro (1). Aquí se adoptará como valor de comparación el más prudente $(1,5 \times 1)$, habitual además en iglesias centroeuropeas coetáneas (10), considerándolo hasta el arranque de bóvedas; ello permitirá tener un referente también para estudiar la esbeltez de los elementos, pese a no estar expresamente aludida en los tratados.

- El carácter de las reglas o criterios establecidos. Las mismas son predominantemente relaciones numéricas entre magnitudes implícitas en el propio dibujo de la planta, del tipo luz/espesor, espesor/saliente en un contrafuerte, etc. A veces también operaban construcciones geométricas basadas en el cuadrado, introduciendo el valor de $\sqrt{ } \mathbf{2}$ en las proporciones resultantes, aunque deben descartarse com- plejos trazados reguladores que controlaran unívocamente el edificio de principio a fin.

- Las reglas y criterios concretos que serían aplicables para dimensionar cada tipo de elemento. En los tratados se partía del coro, una capilla mayor única a modo de cabecera, cuya luz libre venía a ser el «módulo grande» generador de la composición general del edificio, y del que también se obtenía el espesor de su muro perimetral. Éste, a su vez, era utilizado como un «módulo pequeño» para dimensionar los distintos elementos estructurales o formales (2), que así en última instancia también pueden referenciarse a la luz del coro (1). Por ello, a este último parámetro homogenizaremos las distintas relaciones dimensionales recogidas en los tratados, permitiendo no sólo la comparación entre las respectivas fuentes documentales sino también con lo determinado en las trazas estudiadas. Ante la inexistencia de un coro análogo, en éstas se adoptará como valor análogo la luz intereje de la nave central. 
Considerando lo establecido en la tratadística, a continuación se concretan estos tres aspectos para pilares, muros y contrafuertes, conformándose así el conjunto de los criterios con los que se estudiarán los elementos estructurales. También se tendrán presentes algunos indicios existentes en la documentación histórica de las fábricas, así como el propio dibujo y acotado de los elementos en las plantas, que constituye un significativo indicador de los parámetros que interesaban a los maestros (Tabla 1):

- Pilares. La documentación de la fábrica segoviana alude expresamente a la dimensión de los pilares, establecida «en el bivo a diez pies (...) syn las salidas de las sotobasas» (15); esto es, el parámetro que interesaba era su sección típica, definida por su diámetro, y sin considerar las articulaciones formales de encuentro con el suelo ni los recrecidos que suponen las cimentaciones. También en Sevilla los pilares están referidos en los libros de fábrica (16) como de 12 y 13 pies, unas dimensiones coincidentes con el diámetro de los que entonces se construían. Por otro lado, este criterio es coherente con su representación en las respectivas traças, dibujándose sólo los fustes (sin las basas), y con un diámetro que además, en la mayoría de los casos, coincide con las cotas rotuladas en dos de las plantas.

En los tratados tardogóticos, en analogía con los muros, cabría suponer que interesaba también establecer la sección de su fuste. En las Instrucciones y la Medida del Coro su diámetro está en relación al espesor mural de los arcos formeros de la nave central. El primero los iguala, estableciendo explícitamente dos reglas distintas para los pilares de la nave central: $1 / 10$ o $\sqrt{ } 2 \times 1 / 10 \approx 1 / 7$; para una altura hasta cornisas de $1,5 \times 1$, las esbelteces serían respectivamente de 15 y 10,5. En la Medida del Coro el texto es confuso, dando lugar a distintas interpretaciones: Coenen (11) defiende la relación $1 /(1+\sqrt{ } 2) \approx 1 / 2,41$ entre el muro del formero de la nave central y el pilar, suponiendo un pilar de diámetro 2,41 × 1/10 $\approx 1 / 4,1$ (esbeltez de 6,2). En cambio Huerta (2) postula secciones menores: una hipótesis igualaría el espesor del pilar y el del formero de la nave central (1/10 y esbeltez 15 ), y otra que los hace 1,276 veces mayor $(1,276 \times 1 / 10=1 / 7,8)$, suponiendo esto una esbeltez de 11,8.
- Muros. En las dos plantas que tienen cotas, establecen su espesor en el arranque, concordando además con lo dibujado. Se trata de un criterio bien recogido en las Instrucciones de Lechler, que fija el espesor del muro del coro en su arranque, aumentándolo para la cimentación y reduciéndolo a partir de la imposta de las ventanas. El muro lateral del cuerpo de naves se solía fijar a partir de este espesor del coro, existiendo algunas diferencias entre las fuentes. En el Tratado de Viena la regla de 1/10 es universal para todos los muros (esbeltez 15), y, aunque Lechler propone la misma relación, también aconseja sobredimensionar para fábricas de regular calidad; por ultimo en la Medida del Coro el valor se incrementa en un tercio (espesor $1,33 \times 1 / 10=1 / 7,5$ y esbeltez 11,3$)$.

- Contrafuertes. Un informe de la fábrica segoviana (17) apunta a que el parámetro clave a dimensionar era el saliente respecto al muro, aunque con cierta conciencia de que éste también colaboraba mecánicamente ${ }^{6}$. También en los tres tratados tardogóticos se dimensionan por su saliente, obtenido a partir del ancho (10), parámetro éste que solía atender a la regla general para los muros del edificio (1/10). Para los contrafuertes del coro establecen una proporción dupla, regla que hacen extensiva también a los de las naves laterales; esto suponía un saliente de $2 \times 1 / 10=1 / 5$. Lechler además de esta regla general propone otra específica para los de las laterales, cuyo saliente sería equivalente al espesor mural del formero de la nave central, obtenido por dos reglas diferentes: $1 / 10$ y $\sqrt{ } 2 \times 1 / 10 \approx 1 / 7$; la primera opción supone igualar saliente y espesor, y la segunda una relación $\sqrt{ } 2 / 1 \approx 1,4$, más estilizada y frecuente en las trazas centroeuropeas (2).

\section{DIMENSIONAMIENTO ESTRUCTURAL EN LAS TRAZAS}

Se estudia el dimensionamiento absoluto de cada elemento, así como en relación a la luz intereje de la nave central (l), valor que permitirá comparar los distintos casos. En muros y pilares también se analiza la esbeltez, considerando su altura hasta la cota de arranque del sistema de bóvedas, formalizada en el remate de cornisas o capiteles. Por último, el conjunto de aspectos considerados se contrastan con las fábricas finalmente construidas.

Tabla 1. Parámetros de los elementos de la estructura vertical. Determinaciones de los tratados centroeuropeos, valores en las traças e hipótesis de reglas de referencia.

\begin{tabular}{|c|c|c|c|c|c|c|c|c|c|c|c|c|c|c|c|c|c|c|}
\hline & \multirow{3}{*}{$\begin{array}{l}\text { LUZ } \\
\text { (NAVE } \\
\text { o CORO) }\end{array}$} & \multicolumn{4}{|c|}{ PILARES } & \multicolumn{4}{|c|}{ MUROS EXTERIORES } & \multicolumn{4}{|c|}{ MUROS ENTRE CAPILLAS } & \multicolumn{5}{|c|}{ CONTRAFUERTES DE MUROS } \\
\hline & & DIAMET & & \multirow[t]{2}{*}{ ALTURA } & \multirow[t]{2}{*}{ ESBELT. } & \multicolumn{2}{|c|}{ ESPESOR } & \multirow{2}{*}{ ALTURA } & \multirow[t]{2}{*}{ ESBELT. } & \multirow{2}{*}{\multicolumn{2}{|c|}{$\begin{array}{l}\text { ESPESOR } \\
\text { PIES s/ LUZ }\end{array}$}} & \multirow{2}{*}{ ALTURA } & \multirow[t]{2}{*}{ ESBELT. } & \multirow{2}{*}{\multicolumn{2}{|c|}{$\begin{array}{l}\text { SALIENTE } \\
\text { PIES s/ LUZ }\end{array}$}} & \multirow{2}{*}{\multicolumn{2}{|c|}{$\begin{array}{l}\text { ESPESOR } \\
\text { PIES s/ LUZ }\end{array}$}} & \multirow{2}{*}{$\begin{array}{l}\text { RELACION } \\
\text { SAL./ESP. }\end{array}$} \\
\hline & & PIES & s/ LUZ & & & PIES & s/ LUZ & & & & & & & & & & & \\
\hline LECHLER & L & - & $\mathrm{L} / 10-\mathrm{L} / 7$ & $1,5 \times L$ & $15-10,5$ & - & $\mathrm{L} / 10$ & $1,5 \times \mathrm{L}$ & 15 & - & - & - & - & - & $\mathrm{L} / 10-\mathrm{L} / 7$ & - & $\mathrm{L} / 10$ & $1-1,4$ \\
\hline MEDIDA DEL CORO & L & - & $\mathrm{L} / 10-\mathrm{L} / 4,1$ & $1,5 \times L$ & $15-6,2$ & - & $\mathrm{L} / 7,5$ & $1,5 \times \mathrm{L}$ & 11,3 & - & - & - & - & - & $\mathrm{L} / 5$ & - & $\mathrm{L} / 10$ & 2 \\
\hline TRATADO DE VIENA & $A \quad L$ & - & - & $1,5 \times L$ & - & - & $\mathrm{L} / 10$ & $1,5 \times L$ & 15 & - & - & - & - & - & $\mathrm{L} / 5$ & - & $\mathrm{L} / 10$ & 2 \\
\hline INTERVALO & L & - & $\mathrm{L} / 10-\mathrm{L} / 4,1$ & $1,5 \times \mathrm{L}$ & $15-6,2$ & $-\mathrm{L} /$ & $-/ 10-\mathrm{L} / 7,5$ & $51,5 \times L$ & $15-11,3$ & - & - & - & - & - & $\mathrm{L} / 10-\mathrm{L} / 5$ & - & $\mathrm{L} / 10$ & $1-2$ \\
\hline SEVILLA TRAZA & 60 & 12 y 15 & $\mathrm{~L} / 5$ y L/4 & 60 & 5 y 4 & 6 & $\mathrm{~L} / 10$ & 26 & 4,3 & 6 & $\mathrm{~L} / 10$ & 26 & 4,3 & 4 & $\mathrm{~L} / 15$ & 6 & $\mathrm{~L} / 10$ & $4 / 6=0,7$ \\
\hline SEVILLA CONSTR. & 58,5 & 12 y 13 & $\mathrm{~L} / 4,9$ y L/4,5 & .561 & 5,1 y 4,7 & 4 & $\mathrm{~L} / 14,6$ & 26 & 6,5 & 5 & $\mathrm{~L} / 11,7$ & 26 & 5,2 & 2 & $\mathrm{~L} / 29,3$ & 5 & $\mathrm{~L} / 11,7$ & $2 / 5=0,4$ \\
\hline SEGOVIA JUAN GIL & 55 & 10 & $\mathrm{~L} / 5,5$ & 64 & 6,4 & 4,5 & $\mathrm{~L} / 12,2$ & 43 & 9,6 & 4,5 & $\mathrm{~L} / 12,2$ & 43 & 9,6 & 4,5 & $\mathrm{~L} / 12,2$ & 4,5 & $\mathrm{~L} / 12,2$ & 1 \\
\hline SEGOVIA RODR. GIL & 53 & 10 & $\mathrm{~L} / 5,3$ & 65 & 6,5 & 6 & $\mathrm{~L} / 8,8$ & 35 & 5,8 & 6 & $\mathrm{~L} / 8,8$ & 35 & 5,8 & 6 & $\mathrm{~L} / 8,8$ & 6 & $\mathrm{~L} / 8,8$ & 1 \\
\hline SEGOVIA CONSTR. & 51,5 & 10 & $\mathrm{~L} / 5,2$ & 58 & 5,8 & 4,5 & $\mathrm{~L} / 11,4$ & 30 & 6,7 & 6 & $\mathrm{~L} / 8,6$ & 30 & 5 & 4,5 & $\mathrm{~L} / 11,4$ & 5 & $\mathrm{~L} / 10,3$ & $4,5 / 5=0,9$ \\
\hline REGLA PROPUESTA & $A \quad L$ & - & $\mathrm{L} / 5-\mathrm{L} / 4$ & - & $6-4$ & -1 & $\mathrm{~L} / 15-\mathrm{L} / 10$ & - & $10-5$ & $-\mathrm{L}$ & $\mathrm{L} / 15-\mathrm{L} / 10$ & $0-$ & $10-5$ & -1 & $\mathrm{~L} / 30-\mathrm{L} / 9$ & $-L$ & $\mathrm{~L} / 15-\mathrm{L} / 10$ & $0 \quad 0,5-1$ \\
\hline
\end{tabular}

${ }^{6}$ Así se trasluce en un informe de Alonso Rodríguez (1513) tras el derrumbe del cimborrio sevillano (6). 


\subsection{Sevilla: la traça de Bidaurreta}

Las obras de la catedral se iniciarían hacia 1433-1434, a partir de una traça hoy perdida, pero de la que el anónimo "plano de Bidaurreta» parece ser fiel copia a escala 1/240. Éste refleja un gigantesco edificio abovedado de cinco naves y capillas perimetrales, de perímetro rectangular y sin la característica girola semicircular, y contiene información suficiente para establecer una hipótesis del proyecto catedralicio primigenio (6) (Figura 7). Así, los espacios y elementos principales están acotados con cifras romanas en pies ${ }^{7}$, anotándose 60 de luz para la nave central, 40 para las colaterales (ambas intereje de pilares) y 26 para las capillas hornacinas; también se especificaron las alturas totales hasta las claves de las bóvedas, 132 pies para la central, 93 para las colaterales y 51 para las capillas hornacinas, lo que ha permitido deducir la altura prevista para los elementos de la estructura vertical (7) (Figura 3). Las secciones previstas para éstos son expuestas a continuación (Tabla 1):

- Pilares. Los de las naves colaterales se acotaron expresamente con 12 pies de diámetro $(1 / 5)$, y al prevérseles una altura de 60 pies su esbeltez era de $60 / 12=5$. Esta sección se aumentó para los de la nave central, dibujados como de 16 pies, pero cuya cota especificó 15 , suponiendo $1 / 4$ de la luz de la nave central. Pese a que estos últimos ascienden hasta los 90 pies, su altura debe ser considerada similar a los anteriores, ya que a partir de los primeros capiteles el soporte realmente se integra en la masa mural de la arcada; por ello su esbeltez sería de 60/15 = 4 (Figura 8).
- Muros. En la planta se dibujaron todos los muros conformadores de las capillas hornacinas con idéntico espesor, dimensionados en 6 pies según se acotó en el muro del evangelio (1/10). La altura prevista para estos ámbitos era de 26 pies hasta la cornisa, resultando una esbeltez para todos sus muros de $26 / 6=4,33$.

- Contrafuertes. Se dibujaron con un saliente de 4 pies, constituyendo $2 / 3$ partes del muro de 6 pies que refuerzan y $1 / 15$ de la luz de la nave central. Su anchura es la misma que la del muro, suponiendo en definitiva una mera prolongación hacia el exterior del lienzo separador de las capillas hornacinas.

El cuerpo de naves finalmente construido redujo levemente las anchuras (nave central de 58,5 pies, laterales de 39 y capillas 24,5), lo que no justifica la sustancial disminución de las secciones resistentes. Así, el muro perimetral pasó de 6 a 4 pies $(1 / 14,6)$, aunque al mantenerse la altura de las capillas en 26 pies la esbeltez ascendió hasta 26/4=6,5; también los muros entre las capillas del costado de la epístola disminuyeron de 6 a 5 pies (1/11,7 y esbeltez 5,2), aunque se mantuvieron en el otro. Igualmente los contrafuertes perimetrales redujeron su ancho a 5 pies $(1 / 11,7)$ y el saliente de 4 a 2 pies $(1 / 29,3)$, pasando a tener la mitad del espesor del muro que respaldaban. Los pilares laterales se construyeron con los 12 pies previstos $(1 / 4,9)$, pero los de la nave central disminuyeron de 15 a 13 pies $(1 / 4,5)$; al apenas cambiar sus alturas previstas hasta capiteles (61 pies), la esbeltez de los laterales quedó prácticamente igual $(5,1)$, incrementándose notablemente en los centrales por la disminución de su sección $(4,7)$.

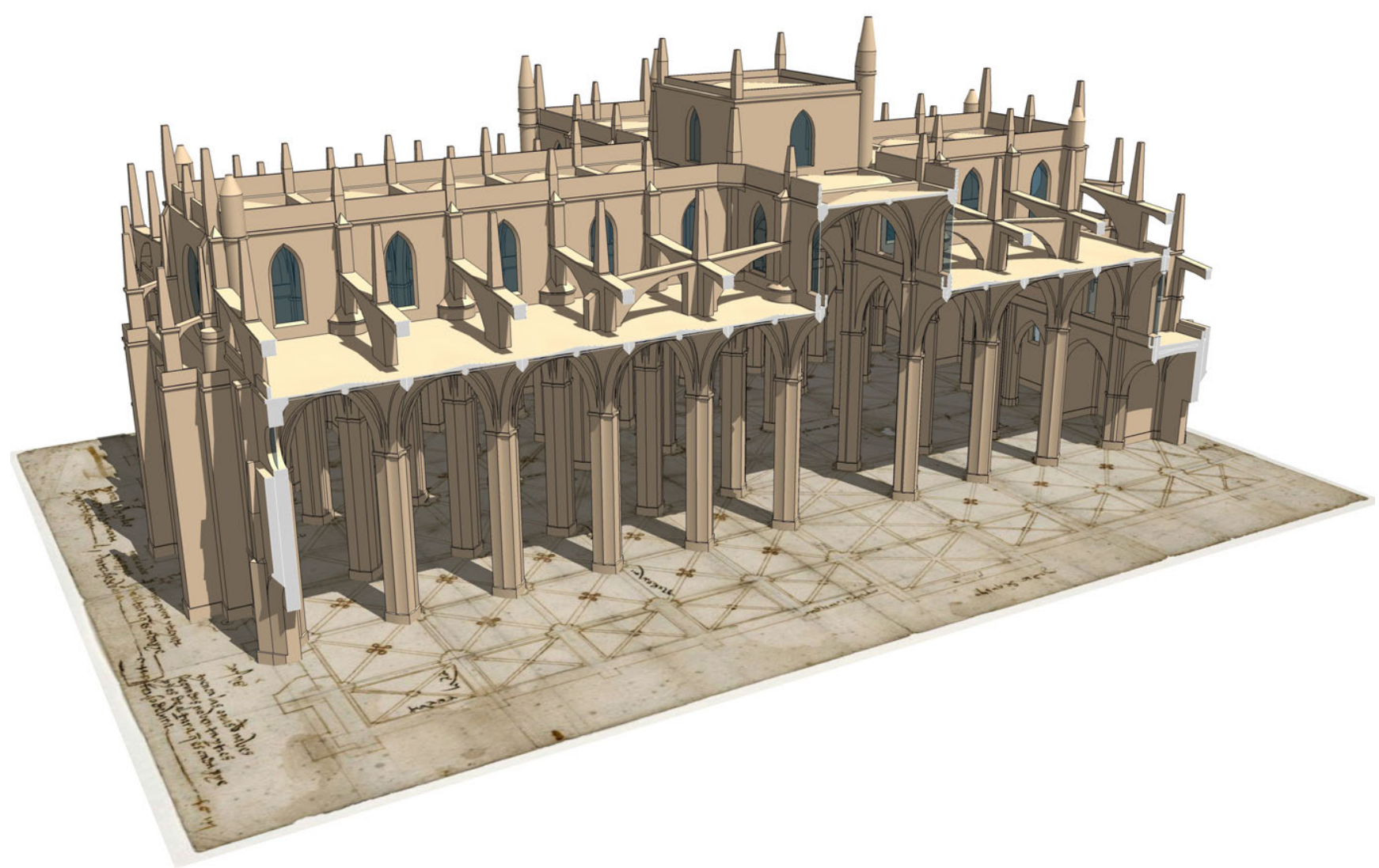

Figura 7. Hipótesis del proyecto catedralicio sevillano a partir del «plano de Bidaurreta» (J. M. Guerrero Vega).

7 Unidad de medida que por el contexto geográfico y temporal debemos entender como el pie castellano, equivalente a 27,86 cm (7). 

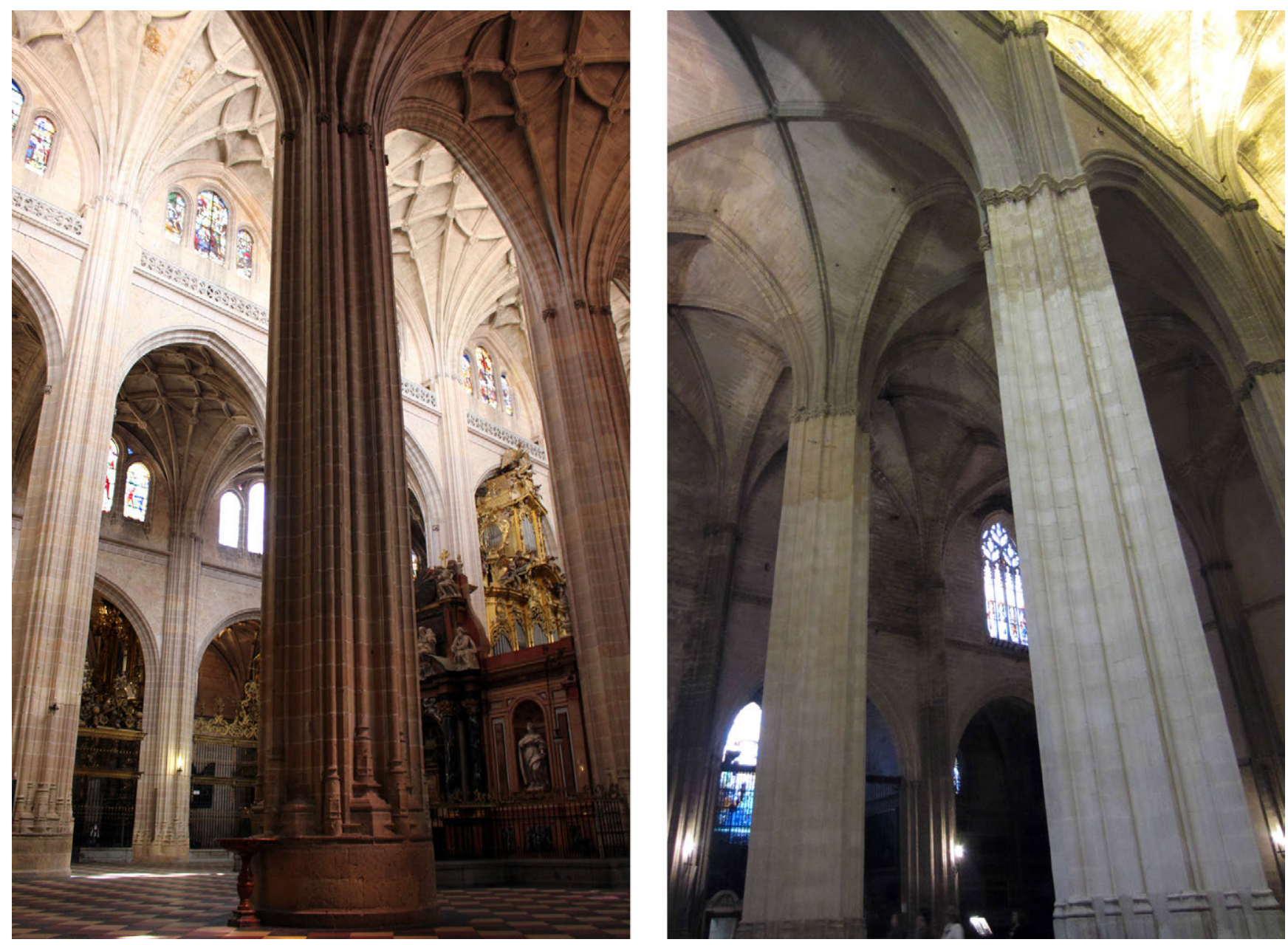

Figura 8. Pilares de las naves central y lateral de la catedral de Sevilla (derecha) y central de la catedral de Segovia (izquierda).

\subsection{Segovia: las primeras trazas de Juan Gil de Hontañón}

El primer proyecto de la catedral quedó recogido en una planta ${ }^{8}$, sin acotar pero a una a escala estimable de $1 / 144$, que realizaría Juan Gil de Hontañón en la primavera de 1524 (Figura 4). Representaba un edificio abovedado de tres naves y capillas hornacinas, con transepto, crucero y cabecera semicircular con capillas radiales. La nave central tenía una anchura intereje de pilares de 55 pies, las laterales 40, y las capillas hornacinas 28 . El maestro también haría una sección transversal del templo a escala $1 / 108^{9}$, estableciendo las alturas de los espacios: la nave central tendría 93,5 pies hasta el arranque de bóvedas, las laterales 64 y las capillas hornacinas 43 . El dimensionamiento previsto para los elementos estructurales fue el siguiente (Tabla 1):

- Pilares. Son de 10 pies $(1 / 5,5)$ dibujándose como fustes circulares con baquetones, y sin grafiar su basa. Pese a que ascienden hasta los 93,5 pies, su altura se considerará también hasta la cota de los primeros capiteles (64 pies), siendo su esbeltez de 64/10 = 6,4 (Figura 8).

- Muros. En la planta se dibujan todos los de las capillas hornacinas con 4,5 pies $(1 / 12,2)$, apoyando en un gran zócalo que sobresalía otro tanto, absorbiendo el saliente del contrafuerte (Figura 9). La altura prevista para estos ámbitos era de 43 pies hasta la cornisa, suponiendo una esbeltez de 9,6 (sin considerar el regrueso que supone el zócalo en los muros exteriores).

- Contrafuertes. Tienen por saliente también 4,5 pies (1/12,2), el mismo que el espesor del muro que respaldan. Atendiendo a un criterio formal, su anchura coincide con la de los muros separadores de las capillas hornacinas (4,5 pies), resultando una proporción cuadrada en planta entre ancho y saliente.

\subsection{Segovia: las nuevas trazas de Rodrigo Gil de Hontañón}

Apenas iniciadas las obras moriría Juan Gil, sucediéndole en la maestría su hijo Rodrigo en septiembre de 1526. Éste debió de realizar la segunda planta conservada ${ }^{10}$ en torno a 1527 , también a escala $1 / 144$, asumiendo el diseño general pero con significativos cambios en cabecera y bóvedas (Figura 5); también las anchuras de las naves variaron levemente, quizás para ajustarse al solar: la central sería de 53 pies, las laterales 39 , y las capillas hornacinas de 29. Esta planta se complementaba también con una elevación ${ }^{11}$ a escala $1 / 108$, que modificó las alturas respecto a la anterior: hasta el arranque de bóvedas la

\footnotetext{
${ }^{8}$ N. ${ }^{\circ} 2$ del Catálogo de Parrondo (18).

9 N. ${ }^{\circ} 4$ del Catálogo de Parrondo (18).

${ }_{10} \mathrm{~N}^{\circ}{ }^{1}$ del Catálogo de Parrondo (18).

${ }^{11}$ N. ${ }^{\circ} 5$ del Catálogo de Parrondo (18).
} 


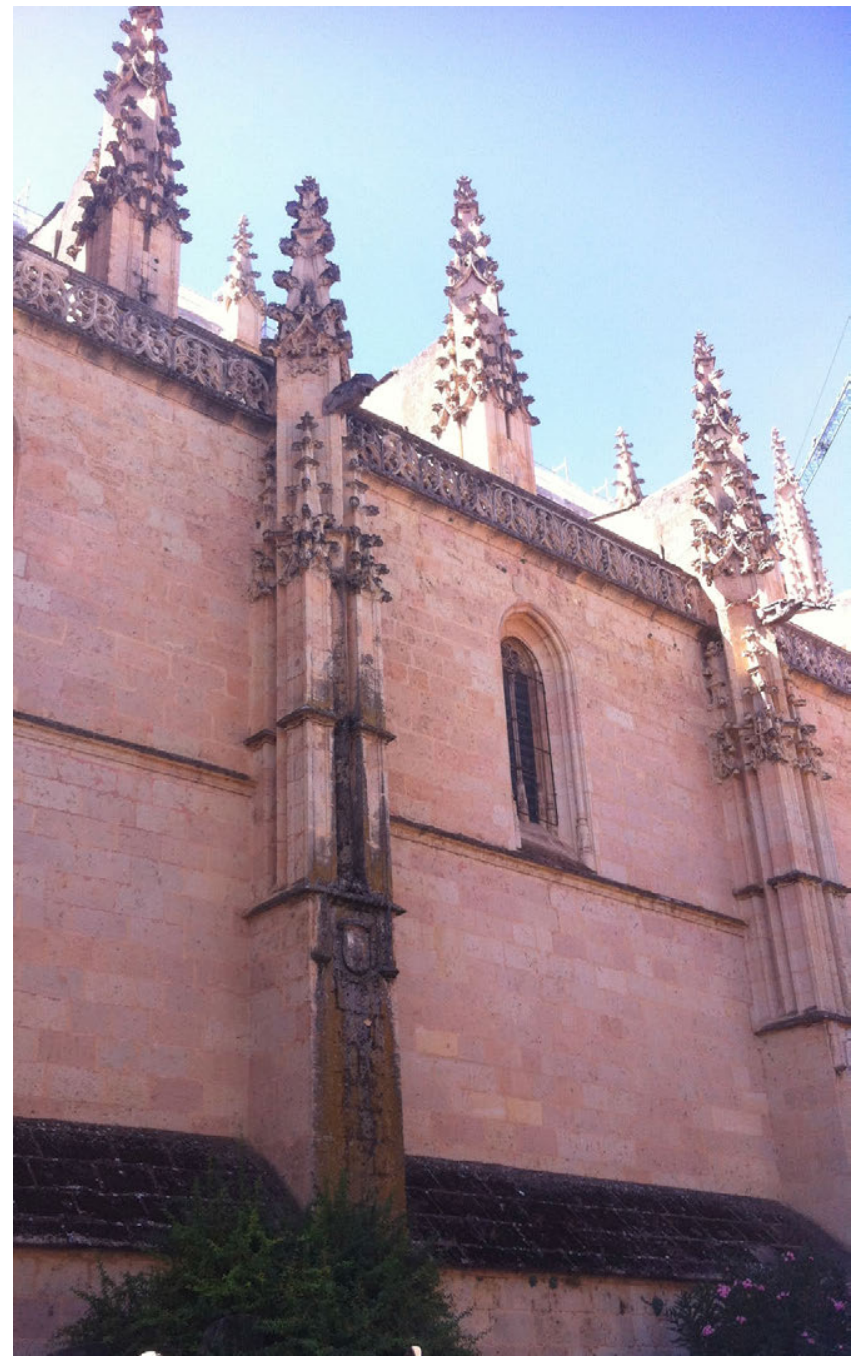

Figura 9. Muro, zócalo y contrafuerte del lienzo lateral norte de la catedral de Segovia.

nave central se incrementaría hasta los 98 pies, las laterales quedarían en un valor similar (65 pies) y las capillas hornacinas descenderían a 35 pies. También las secciones resistentes sufrieron distintos cambios, acotándose algunas en pies $^{12}$, usando números romanos (Tabla 1):

- Pilares. Son dibujados como fustes perfectamente circulares, acotándose explícitamente a 10 pies, coincidiendo con la otra planta. La esbeltez sería muy similar $(6,5)$, considerando la altura hasta los primeros capiteles de las naves laterales (65 pies).

- Muros. Todos los de las capillas hornacinas se incrementaron hasta los 6 pies $(1 / 8,8)$, dimensión acotada explícitamente para los separadores de las mismas. Al ser ahora la altura prevista menor, 35 pies hasta la cornisa, la esbeltez descendió hasta 5,8 (sin considerar el regrueso del zócalo).

- Contrafuertes. Como en la anterior planta, arrancan del zócalo y tienen por saliente un valor equivalente al espesor del muro que refuerzan, pero ahora de 6 pies $(1 / 8,8)$. Su ancho también tiene el mismo valor, asumiendo nuevamente el del muro separador de las capillas hornacinas, resultando una proporción cuadrada en planta.

\subsection{Segovia: comparación de las dos trazas generales y con lo construido}

Las diferencias entre las dos traças, así como con lo finalmente construido, evidencia un uso heterogéneo de las supuestas reglas al uso. El aumento de muros y contrafuertes de la segunda planta no obedece a modificaciones sustanciales en el diseño y dimensiones del cuerpo de naves, siendo además contradictorio con los ajustes altimétricos, que redujeron las capillas; esto también ocurre en los pilares, que mantienen su sección pese a incrementarse la altura de la nave central. En definitiva estamos con criterios de diseño distintos, y en lo que respecta a muros y contrafuertes mucho más conservadores por parte de Rodrigo Gil, que incrementó un 33\% el espesor de todo el sistema estructural (muros y contrafuertes) de las capillas laterales.

Sin embargo, este sobredimensionamiento no fue secundado a la hora de construir el edificio, que redujo levemente sus anchuras (nave central de 51,5 pies, laterales de $37 \mathrm{y}$ las capillas de 26). Las secciones resistentes se establecieron mayoritariamente según la primera planta de Juan Gil (Tabla 1). Así, el muro exterior fue de 4,5 pies con zócalo saliente de igual dimensión, coincidente con el resalto de los contrafuertes $(1 / 11,4)$, cuya anchura no obstante se incrementó moderadamente hasta 5 pies. Sólo el muro separador de las capillas secundó los 6 pies $(1 / 8,6)$ propuestos por Rodrigo, y pese a que su altura se redujo hasta los 30 pies, quedando la esbeltez en 5 . Los pilares de las naves se hicieron con los 10 pies de diámetro previstos en ambas plantas $(1 / 5,2)$, pero al descender la cota de capiteles a 58 pies, la esbeltez bajó también hasta 5,8 .

\subsection{Sevilla y Segovia: analogías y diferencias}

Pese a ciertos parecidos, los dimensionamientos establecidos en los respectivos proyectos no evidencian vínculos claros en los modos de proceder. Atendiendo a lo finalmente construido, las mayores analogías están en las secciones murales: para los exteriores tenemos 4 pies en Sevilla y 4,5 en Segovia, aunque para ambos casos se llegan a proyectar de hasta 6 pies; los separadores de capillas se construyeron de 5 y 6 pies, respectivamente, pero al ser las segovianas más altas, las esbelteces fueron similares.

En los contrafuertes hay un moderado incremento de su saliente entre Sevilla (2/3 del espesor del muro que respaldan) y Segovia (1/1). Aunque esto no es muy coherente con las capillas hornacinas finalmente construidas, muy similares en anchura y altura, sí con lo proyectado inicialmente, ya que Juan Gil las proponía espacios mucho más esbeltos (alto/ancho $=1,5$ ) que los sevillanos (alto/ancho $=1 / 1$ ). En la anchura de estos elementos, por contra, permanece la costumbre de la adopción explícita, o con leves diferencias, del espesor del muro entre capillas hornacinas.

Los pilares, por último, son los únicos elementos en los que se percibe cierta optimización en el tiempo que transcurrió entre ambos edificios, experimentando una reducción significativa: frente a los 13 pies de la nave central sevillana (proyectados incluso de 15 pies) tenemos 10 para Segovia, solventando luces y alturas muy similares; por ello la esbeltez ascendió de 4,7 a 5,8 .

\footnotetext{
${ }_{12}$ Aunque pudo tratarse del pie segoviano $(27,93 \mathrm{~cm})$, el análisis se hará nuevamente con el castellano (27,86 cm), prácticamente coincidente y más común.
} 


\section{REGLAS ESTRUCTURALES. SÍNTESIS Y CONTEXTUALIZACIÓN EN LA TRATADÍSTICA TARDOGÓTICA}

El análisis de las tres plantas permite establecer un rango de valores de referencia, y que comparados con la tratadística centroeuropea evidencian significativas diferencias de criterios. Éstos son generalmente más conservadores en el caso peninsular, algo que no puede achacarse sólo a las diferencias tipológicas con el modelo centroeuropeo que subyace en los tratados, de iglesia salón con tres naves a similar altura y sin capillas laterales.

Los diámetros aconsejados para los pilares en la tratadística tardogótica oscilan ampliamente entre $1 / 10$ y l/4,1, estando para nuestro contexto prácticamente en este último extremo, el más prudente: entre los 1/5,5 propuestos por Juan Gil para Segovia (l/5,1 construido) y $1 / 4$ proyectado para Sevilla $(1 / 4,5$ construido). También las esbelteces centroeuropeas, entre 15 y 6,2, son mucho mayores, ya que el rango hispano oscilaba entre 4 para los pilares centrales sevillanos (4,7 construido) y 6,5 para los propuestos por Rodrigo Gil ( 5,8 construido).

Los espesores de los muros laterales de la tratadística varían entre $1 / 7,5$ y l/10, tendiendo a ser más gruesos que los peninsulares (entre 1/8,8 de Rodrigo Gil para Segovia y 1/14,6 construido en Sevilla). Sin embargo, las alturas previstas son comparativamente inferiores, derivando en una esbeltez muchísimo más conservadora en nuestro caso: respecto al intervalo de los tratados (11,3-15) tendríamos el español entre 4,3 (proyecto para Sevilla) y 9,6 (Juan Gil para Segovia).

Sólo para los contrafuertes se establece un dimensionamiento claramente menor. El saliente en los tratados se establecía entre $1 / 10$ y el posiblemente más habitual de $1 / 5$, contrastando con el amplio rango hispano, entre 1/8,8 de Rodrigo Gil para Segovia y los 1/29,3 construidos en Sevilla. Sin embargo, el intervalo se reduce considerablemente si consideramos el saliente en relación al propio ancho del contrafuerte: esta proporción en los tratados está entre 1 y 2, mientras las peninsulares son menos estilizadas, entre 0,4 (construido en Sevilla) y 1 (en las dos plantas segovianas). Las dimensiones del resalto también son menores en relación al muro que respaldan: entre 0,5 y 1 en España, frente al rango entre 1 y 2 de los tratados.

Finalmente, en función de los valores detectados en las trazas y lo realmente construido podrían proponerse unas reglas de dimensionamiento orientativas para el caso español, aproximando los resultados a relaciones sencillas de números enteros (Tabla 1). En los pilares interesaría fijar el diámetro del fuste, estando entre $1 / 4$ y l/5 de la luz intereje a salvar, y dándoles una altura entre 4 y 6 veces de dicho diámetro. Los muros exteriores se dimensionarían en su arranque, estando en torno a 1/10-1/15 de la luz de la nave central, con esbelte- ces muy variables (entre 5 y 10). Este espesor sería aplicable también a otros lienzos, como los separadores de capillas, y al ancho de los contrafuertes, habitualmente una mera continuación hacia el exterior de aquellos. Su resalto respecto al muro sería el valor clave de su dimensionamiento, pudiendo establecerse en función de su ancho, frecuentemente entre la mitad y un valor equivalente.

\section{CONCLUSIONES}

Los casos estudiados apuntan a que en el contexto peninsular no había firmes criterios asentados, utilizándose con flexibilidad las supuestas reglas al uso, llegando a dimensionamientos tan dispares como los dos de Segovia, para un mismo problema. También sorprende la sustancial reducción de las secciones proyectadas al materializarse, quizás por una consideración más detallada y específica de cada elemento, atendiendo también a su cualificación constructiva. Por otro lado, la comparación entre las dos catedrales sugiere que la evolución en el tiempo debió de ser escasa; sólo en los pilares se percibe mayor atrevimiento. En analogía con la tratadística considerada, las reglas se basarían en sencillas relaciones de proporción y, ante la inexistencia del coro centroeuropeo, pudieron estar referidas a la luz intereje de la nave central. No obstante, los dimensionamientos son más conservadores, algo manifiesto en los pilares y muros, mucho menos esbeltos, y los primeros comparativamente más gruesos en relación a las luces a salvar. Sólo los contrafuertes son menores, algo coherente con la existencia de sólidas capillas laterales, que suponían un eficaz contrarresto del cuerpo de naves.

El proceso de diseño del edificio gótico comenzaba con un dibujo general de la planta. El mismo, además de organizar espacios, suponía un primer dimensionamiento de los elementos estructurales, así como su racionalización y coordinación formal y dimensional. Por ello no debe sorprender que sus dimensiones siempre se acoten en la planta, algo además coherente con los tratados tardogóticos, cuyas reglas aluden a parámetros implícitos en la misma. Una buena traça, en definitiva, permitiría comenzar el edificio con razonables garantías de viabilidad, incluso en el habitual caso de importantes cambios, como ocurrió en Segovia, con las obras ya comenzadas. Esto, a la postre, evidencia la confianza de los maestros góticos en las reglas de dimensionamiento utilizadas, así como que, aun sin conocimientos para comprenderlo, debieron de ser conscientes de que las secciones resistentes eran válidas para un cierto rango de luces y cargas.

\section{AGRADECIMIENTOS}

Este trabajo se enmarca en el Proyecto I+D+i del MINECO (HAR2012-35152/ARTE): «Gótico catedralicio sevillano. Arquitectura y ciudad en los ámbitos de influencia de la Catedral de Sevilla».

\section{REFERENCIAS}

(1) Heyman, J. (1966). The Stone Skeleton. International Journal of Solids and Structures, 2: 249-279, doi: https://doi. org/10.1016/0020-7683(66)90018-7.

(2) Huerta, S. (2007, 7-9 de junio). Las reglas estructurales del gótico tardío alemán. En Actas del Quinto Congreso Nacional de Historia de la Construcción, 2: 519-532. Burgos: Instituto Juan de Herrera, CEHOPU y CEDEX.

(3) García, S. (1681). Compendio de Architectura y Simetría de los Templos conforme a la medida del cuerpo humano con algunas demostraciones de Geometría. Madrid: Biblioteca Nacional de España, Ms. 8884. 
(4) Jiménez, A. (2013). Anatomía de la catedral de Sevilla, pp. 28 y 113. Sevilla: Diputación de Sevilla.

(5) Ruiz, J. A. (2003). Las trazas de la catedral de Segovia. Segovia: Caja Segovia y Diputación Provincial de Segovia.

(6) Alonso, B., Jiménez, A. (2009). La Traça de la Iglesia de Sevilla. Sevilla: Cabildo Metropolitano.

(7) García-Ortega, A. (2014). El proyecto gótico de la catedral de Sevilla. Indicios de trazado, medida y proporción. EGA, Revista Expresión Gráfica Arquitectónica, 23: 184-193, doi: http://dx.doi.org/10.495/ega.2014.1751.

(8) Jiménez, A. (2011). El arquitecto tardogótico a través de sus dibujos. En Alonso, B. (Ed.), La arquitectura tardogótica castellana entre Europa y América (pp. 389-416). Madrid: Sílex.

(9) Ramos, A. (2015). Caracterización estructural de los rellenos situados en el trasdós de bóvedas de edificios históricos (Tesis doctoral). Madrid: Universidad Politécnica de Madrid. http://oa.upm.es/38758/.

(10) Shelby, L. R., Mark, R. (1979). Late gothic structural design in the "Instructions" of Lorenz Lechler. Architectura, 9(2): $113-131$.

(11) Coenen, U. (1990). Die spätgotischen Werkmeisterbücher in Deutschland. Untersuchung und Edition der Lehrschriften für Entwurf und Ausführung von Sakralbauten. Munich: Scaneg.

(12) Lechler, L. (1516). Unterweisung. Historisches Archiv, Handschrift Wf. 276. Colonia.

(13) Huerta, S., Aroca, R. (1990). Cúpulas de fábrica. Un estudio de sus dimensiones y semejanzas. Ingeniería Civil, 75: 109123.

(14) Mainstone, R. J. (1968). Structural theory and design before 1742. The Architectural Review, CXIII(854): 303-310.

(15) Egas, E. (1532, 5 de marzo). Informe sobre la marcha de las obras de la catedral de Segovia. Archivo de la Catedral de Segovia, G/61.

(16) Archivo de la Catedral de Sevilla, Fondo Capitular, Fábrica 09339, fol. 69.

(17) Colonia, F. de (1536, 15 de febrero). Visitación que hizo Françisco de Colonya de la obra de la iglesia de Segovia. Archivo de la Catedral de Segovia, G/61.

(18) Parrondo, C. (1975). Catálogo de la exposición de trazas para la catedral de Segovia, Segovia: Publicaciones de la Diócesis de Segovia. 